\title{
Experimental Study of the Quantification of Indocyanine Green Fluorescence in Ischemic and Non-Ischemic Anastomoses, Using the Sergreen Software Program
}

Xavier Serra-Aracil ( $\nabla$ xserraa@gmail.com )

Corporació Sanitària Parc Taulí

Albert García-Nalda

Corporació Sanitària Parc Taulí

Borja Serra-Gomez

Corporació Sanitària Parc Taulí

Alvaro Serra-Gomez

Corporació Sanitària Parc Taulí

Laura Mora-Lopez

Corporació Sanitària Parc Taulí

Anna Pallisera-Lloveras

Corporació Sanitària Parc Taulí

Victoria Lucas-Guerrero

Corporació Sanitària Parc Taulí

Salvador Navarro-Soto

Corporació Sanitària Parc Taulí

\section{Research Article}

Keywords: Perfusion, ICG, fluorescence, vascularization, quantification, bowel ischemia

Posted Date: September 22nd, 2021

DOI: https://doi.org/10.21203/rs.3.rs-880156/v1

License: (c) (i) This work is licensed under a Creative Commons Attribution 4.0 International License. Read Full License 


\section{Abstract}

Background: Tissue ischemia is a key risk factor for anastomotic leakage (AL). Indocyanine green (ICG) is widely used in colorectal surgery to define the segments with the best vascularization. In an experimental model, we present a new system for quantifying ICG saturation, SERGREEN software.

Methods: This was a controlled experimental study with eight pigs. In the initial control stage, ICG saturation was analyzed at the level of two anastomoses in the right and left colon. Control images of the two segments were taken after ICG administration. The images were processed with the SERGREEN program. Then, in the experimental ischemia stage, the inferior mesenteric artery was sectioned at the level of the anastomosis of the left colon. Fifteen minutes after the section, sequential images of the two anastomoses were taken every 30 ' for the following $2 \mathrm{~h}$.

Results: At the control stage, the mean scores were 134.2 (95\% Cl: 116.3-152.2) for the right colon and 147 (95\% Cl: 134.7-159.3) for the left colon ( $p=0.174)$. The right colon remained stable throughout the experiment. In the left colon, saturation fell by 47.9 points with respect to the preischemia value $(p<0.01)$. After the first postischemia determination, the values of the ischemic left colon remained stable throughout the experiment. The relative decrease in ICG saturation of the ischemic left colon was $32.6 \%$.

Conclusions: The SERGREEN program quantifies ICG saturation in normal and ischemic situations and detects differences between them. A reduction in ICG saturation of $32.6 \%$ or more was correlated with complete tissue ischemia.

\section{Introduction}

In recent years, technological advances have allowed the development of many new instruments for performing more effective and safer surgeries.

In laparoscopic surgery, indocyanine green (ICG) is widely used to improve the evaluation of tissue viability. As this fluorescent compound can also be applied in open surgery, it is a particularly valuable surgical aid. However, its applicability has been limited by the subjectivity inherent in its evaluation; despite attempts at standardization, its assessment remains highly observer-dependent []. In colorectal surgery, ICG is mainly used to study the vascularization of the intestinal segments for creating anastomoses. Poor intestinal vascularization can lead to ischemia, which may cause perforation due to necrosis and anastomotic leakage.

The present experimental study was designed to evaluate the clinical applicability of the SERGREEN program, a genuine software program developed by our research team that provides an objective method for quantifying ICG and reflecting the state of tissue vascularization. The main objective was to assess the differences in tissue perfusion around the anastomosis in two segments: one normal segment and one ischemic segment. The ischemic segment was created by dividing the inferior mesenteric artery, and changes in intestinal vascularization were assessed.

\section{Material And Methods}

\section{Ethical statement}

The study was approved by the Ethics Commission for Animal and Human Experimentation of the Autonomous University of Barcelona, to which our hospital is affiliated (Ref. CEEAH 10; 26-2016) 


\section{Study design}

Experimental, controlled, prospective study in animals. After laparoscopic surgery and ICG administration, the vascularization of the colon was quantitatively determined using instantaneous images with the SERGREEN program. All methods were carried out in accordance with relevant guidelines and regulations. This study followed the ARRIVE (Animal Research: Reporting of In Vivo Experiments) guidelines.

Eight farm pigs (Large-White breed: four males and four females, weight 30-35 kg and age 2-4 months) were used. They were imported from SPECIFIC PIGS Ltd. (CIF-B65488017. Autovia de Castelldefels Km. 31, El prat de Llobregat, 08820, (Barcelona), SPAIN) with all the required health and transport documentation. The use of all pigs were allowed by informed consent from SPECIFIC PIGS Ltd.

\section{Experimental procedures}

Animals were operated upon at the Experimental Surgery Unit of the Parc Taulí University Hospital by the hospital's colorectal surgery team, with support from the veterinary team. The surgery was performed under general anesthesia in accordance with the center's animal anesthesia protocol.

Sedation was performed by intramuscular injection of zolethyl 100 ( $2 \mathrm{mg} / \mathrm{kg}$ tiletamine $+2 \mathrm{mg} / \mathrm{kg}$ zolazepam), xylazine $(2 \mathrm{mg} / \mathrm{kg})$ and atropine $(0.01 \mathrm{mg} / \mathrm{kg})$. The atrial vein was channeled, and propofol was injected in a bolus $(1.5 \mathrm{mg} / \mathrm{kg})$. Once the animals were sedated and relaxed, orotracheal intubation was performed. Sedation and analgesia were maintained by a continuous infusion pump using propofol and fentanyl, and fluid therapy was maintained with Ringer's lactate solution.

Animals' vital signs were recorded at baseline, after anesthesia, analgesia and relaxation, and prior to surgery. They were maintained stable throughout the procedure, with heart rates ranging between $70-95$ beats per minute and mean blood pressure between 60 and 80 .

The laparoscopic equipment used was the IMAGE 1 H3-Z FI and IMAGE 1 HUB HD Camera Control Unit SCB (KarlStorz $\left.{ }^{\circledR}\right)$. Pictures were taken in STANDARD, SPECTRA A and ICG mode. Images were recorded from the time just prior to the infusion until the end of the procedure.

Two groups were created for the study of the anastomoses. The control group underwent two phases of surgery, one open and one laparoscopic; in the second group, which also underwent open and laparoscopic surgery, an ischemic segment was created at the level of the left colon, while the anastomosis of the right colon was left undisturbed.

All the experimental procedures were carried out by the same members of the research team at the same ICG dose, with the same observation time and the same light source and laparoscopic optic exposure. In view of the drug's technical specifications and elimination half-life, a 30-minute interval was observed between each determination and each new administration to ensure adequate clearance of the blood flow.

\section{CONTROL GROUP}

\section{Open phase}


A midline laparotomy was performed, and the right colon and left colon segments of interest were located. The second loop of the right colon (spiral) and the segment of the left colon located in the center of the arcade of the inferior mesenteric artery and vein were selected. Both colon segments were sectioned and anastomosed again using a running end-to-end $3 / 0$ silk suture.

After creation of the anastomoses, the laparotomy was closed with a running, hand-sewn 0 silk suture.

\section{Laparoscopy phase}

Ten-millimeter laparoscopic trocars were inserted at the level of the mesogastrium to the right of the midline laparotomy incision to allow introduction of the laparoscopic camera. A 10-mm trocar in the right quadrant and a 5$\mathrm{mm}$ trocar in the left quadrant were used to introduce the laparoscopic equipment. Intra-abdominal pressure was kept constant with a $12 \mathrm{mmHg}$ self-regulating insufflator.

The ICG was injected at a dose of $0.2 \mathrm{mg} / \mathrm{kg}$ through the atrial vein, and video and image recordings began. Starting two minutes after contrast infusion, standard and Spectra An images were taken of both the right and left colon anastomoses. (Fig. 1)

\section{ISCHEMIA GROUP}

\section{Open phase}

Thirty minutes after the administration of the first dose of ICG, the abdominal cavity was accessed again through midline laparotomy performed earlier. At the level of the anastomosis of the left colon, the arcade of the mesenteric artery and vein was divided less than $5 \mathrm{~cm}$ proximal and $5 \mathrm{~cm}$ distal from the anastomosis, creating an area of approximately $10 \mathrm{~cm}$ without vascularization.

After dividing the artery, the midline laparotomy was closed again using a running suture 0-silk. We waited 15 minutes to ensure complete ischemia of the segment of interest.

\section{Laparoscopy phase.}

A $0.2 \mathrm{mg} / \mathrm{kg}$ dose of ICG was again administered through the atrial vein. Starting two minutes after contrast infusion, Standard and Spectra An images were taken of the two anastomoses (right colon and ischemic left colon).

This procedure was repeated every 30 minutes under the same conditions for up to a maximum of 120 minutes (135 minutes after the vascular section) (Fig. 2-A and 2-B).

\section{Experimental outcomes: The SERGREEN software}

The results were analyzed using the SERGREEN program, measuring the segments of interest in areas of uniform vascularization two minutes after ICG injection. The program was created using the MATLAB-2014b software tool (R2014b, 8.4.0. 150421. 64-bit -maci64- September 15, 2014). 
The images obtained during the experimental procedure were recorded in * jpg format with laparoscopy equipment. This format is processed by the computer program and broken down into three matrices according to the RGB (red, green, blue) color model. Each cell in each matrix corresponds to a pixel with its respective intensity in these three colors. All pixels obtain 24 bits (eight in each matrix) with the information from the three colors.

On the decimal scale, eight bits are represented from 0 to 255 , and this is how these values are

represented. By overlapping the three channels from the RGB image, we obtain the color seen in the original image. SERGREEN processes the matrix corresponding to green and compares it

with the other two to determine the predominant color.

Pixels whose predominant color is not green are discarded. In this way, false readings caused by

reflections are avoided, since white is the composition of the three colors at their maximum value (R: 255 , G: 255 and B: 255).

The program's main tool allows users to mark a rectangle wherever they like in the image and obtain statistical information on the intensity of the green in that region. All the pixels corresponding to the green channel within the specified rectangle can be exported into an Excel file. Another document is generated to check the image selected, as well as a boxplot chart, a histogram and a summary of the central tendency values.

Experimental outcomes: Image processing and analysis of the results obtained with SERGREEN

This measurement was carried out in 10 different areas with $10 \times 10$ pixel squares. A sampling of different areas of interest was generated within the same intestinal segment to ensure its correct representation. A matrix was obtained

that included the eight pigs, all their intestinal segments and their 10 measurements according to area of interest and for each time of observation, including all the pixels contained in the squares.

At the level of the anastomosis, between 1-2 cm proximal and distal to the suture line, 10 areas of interest were recorded in all the images obtained of both the right and left colon, avoiding the areas that correspond to visible vessels (Fig. 3).

\section{Statistical and calculation methods}

The ICG saturation obtained by applying the SERGREEN program to the images of interest was taken as the main variable. The Kolmogorov-Smirnov test was applied to check the normal distributions.

The results are expressed as the means for each segment (the sample mean of the pigs for each segment and observation time).

Student's t test was used for comparisons between two means, while ANOVA was used to compare different means since the distributions were comparable to normal. The decreases in the saturation of the ICG after generating the ischemic area are expressed in absolute and relative terms.

The absolute mean ICG saturation decrease (AMISD) was calculated as the mean ICG saturation of the preischemic left colon (MISPrel = Mean ICG Saturation Prelschemia) minus the mean ICG saturation of all postischemic left colon saturation determinations (MISPostl = Mean ICG Saturation Postlschemia). 


$$
\text { AMISD }=\text { MISPreI }- \text { MISPostI }
$$

We describe the relative mean ICG saturation decrease (RMISD), which is calculated as the unit minus the division of the nonvascularized area (MISPostl) with respect to the vascularized area (MISPrel) of the left colon. This can be expressed as a percentage of the relative decrease by multiplication by 100 .

$$
R M I S D=\left(1-\frac{\text { MISPostI }}{\text { MISPreI }}\right) x 100
$$

\section{Results}

Data from the eight pigs were recorded. Data from the inferior mesenteric artery section in pig 3 and from minute 105 postischemia in pigs 2 and 8 were excluded due to cardiorespiratory arrest in these three cases.

The results for the two groups are presented below, and the preischemia and postischemia results were compared.

\section{CONTROL GROUP}

\section{Right colon}

The mean saturation of the right colon was 134.2 (95\% Cl: 116.3-152.0). The mean preischemia ICG saturations in the right colon for each pig are displayed in Table 1.

Table 1

Summary of the mean saturations in the right colon and left colon during the control period, prior to the section of the inferior mesenteric artery and vein.

\begin{tabular}{|lll|}
\hline \multicolumn{2}{|l|}{ ICG saturation } \\
\hline No pig & Right colon pre-ischemia & Left colon pre-ischemia \\
\hline 1 & 152.57 & 156.90 \\
\hline 2 & 159.43 & 137.10 \\
\hline 3 & 143.42 & 167.29 \\
\hline 4 & & \\
\hline 5 & 103.08 & 137.39 \\
\hline 6 & 121.19 & 130.66 \\
\hline 7 & 130.77 & 143.49 \\
\hline 8 & 128.72 & 155.99 \\
\hline
\end{tabular}

\section{Left colon}


The median saturation of the left colon was 147 (95\% Cl: 134.7-159.3). The mean preischemia ICG saturations in the left colon for each pig are also displayed in Table 1.

There were no statistically significant differences between the mean ICG saturations of the right colon and the left colon prior to the creation of ischemia; the two segments were comparable $(p=0.174)$.

\section{POST-ISCHEMIA GROUP}

\section{Right colon}

In the right colon, no differences were detected between the different observation times during the procedure; the scores remained stable throughout all the experiments (mean: 140; 95\% Cl: 134.2-145.7. ANOVA p $=0.889)($ Figure 4).

The mean values for the right colon for each pig and each observation time are displayed in Table 2.

\section{Table 2}

Summary of the means for each pig and observation time in the left colon during the period of intestinal ischemia.

\begin{tabular}{|c|c|c|c|c|c|c|c|c|c|c|}
\hline \multicolumn{6}{|c|}{ Right colon ICG saturation } & \multicolumn{5}{|c|}{ Left colon ICG saturation } \\
\hline $\begin{array}{l}\mathrm{N}^{0} \text { of pig } \\
/ \text { Time } \\
\text { after } \\
\text { cutting } \\
\text { the IMA } \\
\text { (minutes) }\end{array}$ & 15 & 45 & 75 & 105 & 135 & 15 & 45 & 75 & 105 & 135 \\
\hline 1 & 163.80 & 156.84 & 170.54 & 155.68 & 162.36 & 74.27 & 102.50 & 112.06 & 78.92 & 89.75 \\
\hline 2 & 174.84 & 167.98 & 165.34 & & & 126.93 & 135.27 & 136.91 & & \\
\hline \multicolumn{11}{|l|}{3} \\
\hline 4 & 126.81 & 134.46 & 136.31 & 129.70 & 126.07 & 90.72 & 83.40 & 82.15 & 85.21 & 90.04 \\
\hline 5 & 99.80 & 126.00 & 128.37 & 133.71 & 122.30 & 87.42 & 97.17 & 84.61 & 97.46 & 90.70 \\
\hline 6 & 123.98 & 129.96 & 132.34 & 129.63 & 138.74 & 107.12 & 102.60 & 104.77 & 103.61 & 104.70 \\
\hline 7 & 133.30 & 138.58 & 141.98 & 142.63 & 143.20 & 91.04 & 111.16 & 93.94 & 94.16 & 96.59 \\
\hline 8 & 151.93 & 146.11 & 145.57 & & & 91.04 & 112.39 & 112.99 & & \\
\hline
\end{tabular}

Student's t-test comparing the control observation of the right colon and each of the subsequent observation times did not show statistically significant differences (Table 3).

\section{Table 3}

Summary of the means of each observation time on the right colon and comparison of each one with the control time: all comparisons presented statistically significant differences. 


\begin{tabular}{|c|c|c|c|c|c|c|c|}
\hline & $\begin{array}{l}\text { Vascular } \\
\text { condition }\end{array}$ & $\mathrm{N}$ & Mean & $\begin{array}{l}\text { Estándar } \\
\text { ddeviation }\end{array}$ & $\begin{array}{l}\text { Sig. } \\
\text { (bilateral) }\end{array}$ & $\begin{array}{l}95 \% \mathrm{Cl} \text { of } \mathrm{tl} \\
\text { difference }\end{array}$ & \\
\hline Normal right colon & Pre-ischemia & 7 & 134.1686 & 19.31546 & & Lower & Upper \\
\hline $\begin{array}{l}\text { Right colon } 15^{\prime} \text { after } \\
\text { cutting IMA }\end{array}$ & $\begin{array}{l}\text { Post- } \\
\text { ischemia }\end{array}$ & 7 & 139.2086 & 25.85135 & .687 & -31.61512 & 21.53512 \\
\hline $\begin{array}{l}\text { Right colon } 45^{\prime} \text { after } \\
\text { cutting IMA }\end{array}$ & $\begin{array}{l}\text { Post- } \\
\text { ischemia }\end{array}$ & 7 & 142.8471 & 15.14686 & .368 & -28.89268 & 11.53554 \\
\hline $\begin{array}{l}\text { Right colon } 75^{\prime} \text { after } \\
\text { cutting IMA }\end{array}$ & $\begin{array}{l}\text { Post- } \\
\text { ischemia }\end{array}$ & 7 & 145.7786 & 16.24581 & .247 & -32.39476 & 9.17476 \\
\hline $\begin{array}{l}\text { Right colon } 105^{\prime} \text { after } \\
\text { cutting IMA }\end{array}$ & $\begin{array}{l}\text { Post- } \\
\text { ischemia }\end{array}$ & 5 & 138.2700 & 11.07933 & .681 & -25.65616 & 17.45330 \\
\hline $\begin{array}{l}\text { Right colon } 135^{\prime} \text { after } \\
\text { cutting IMA }\end{array}$ & $\begin{array}{l}\text { Post- } \\
\text { ischemia }\end{array}$ & 5 & 138.5340 & 15.87755 & .688 & -27.87441 & 19.14355 \\
\hline Normal left colon & Pre-ischemia & 7 & 146.9743 & 13.29278 & & Lower & Upper \\
\hline $\begin{array}{l}\text { Left colon } 15^{\prime} \text { after } \\
\text { cutting IMA }\end{array}$ & $\begin{array}{l}\text { Post- } \\
\text { ischemia }\end{array}$ & 7 & 95.5057 & 16.83993 & .000 & 33.80077 & 69.13637 \\
\hline $\begin{array}{l}\text { Left colon } 45^{\prime} \text { after } \\
\text { cutting IMA }\end{array}$ & $\begin{array}{l}\text { Post- } \\
\text { ischemia }\end{array}$ & 7 & 106.3557 & 15.99919 & .000 & 23.48885 & 57.74829 \\
\hline $\begin{array}{l}\text { Left colon } 75^{\prime} \text { after } \\
\text { cutting IMA }\end{array}$ & $\begin{array}{l}\text { Post- } \\
\text { ischemia }\end{array}$ & 7 & 103.9186 & 19.07877 & .000 & 23.90663 & 62.20480 \\
\hline $\begin{array}{l}\text { Left colon } 105^{\prime} \text { after } \\
\text { cutting IMA }\end{array}$ & $\begin{array}{l}\text { Post- } \\
\text { ischemia }\end{array}$ & 5 & 91.8720 & 9.82825 & .000 & 39.41066 & 70.79391 \\
\hline $\begin{array}{l}\text { Left colon } 135^{\prime} \text { after } \\
\text { cutting IMA }\end{array}$ & $\begin{array}{l}\text { Post- } \\
\text { ischemia }\end{array}$ & 5 & 94.3560 & 6.42648 & .000 & 38.17602 & 67.06055 \\
\hline
\end{tabular}

\section{Left colon}

In the left colon, differences were detected between the mean control observation and the mean of all postischemic determinations $(p<0.01)$ (Figure 4$)$.

No differences were detected between observation times within the ischemia period, which remained stable throughout the experiment after dividing the vascular arcade (mean: $99.1 ; 95 \% \mathrm{Cl}: 93.5-104.7$; ANOVA $p=0.385$ ). The mean values for the left colon in each pig and each observation time are displayed in Table 2.

Comparison of the control observation in the left colon with each of the subsequent observations throughout the experiment revealed statistically significant differences (Table 3 ).

The absolute mean decrease in the ICG saturation of the left colon was 47.9 points (95\% Cl: 35.2-60.6), and the relative decrease between ischemia and nonischemia was $32.6 \%$. 


\section{AMISD $=$ MISPreI - MISPostI $=146.9743-99.0839=47.8904 \simeq \mathbf{4 7 . 9}$}

$\boldsymbol{R M I S D}=\left(1-\frac{\text { MISPostI }}{\text { MISPreI }}\right) \times 100=\left(1-\frac{99.0839}{146.9743}\right) \times 100=32.5842001 \simeq \mathbf{3 2 . 6} \%$

\section{Discussion}

Over the last decade, the use of ICG to detect alterations in intestinal perfusion and to reduce its inherent complications has increased. In the reports published in the literature, the aim has always been to try to detect these areas of hypoperfusion. However, the evaluation of the images has always been dependent on the subjective opinions of the raters.

In the search for greater objectivity, ordinal scales have been described for the assessment of saturation. Sherwinter et al $\left.{ }^{2}\right]$ graded saturation based on the absence of green and/or the degree of apparent perfusion.

To avoid this subjectivity in the interpretation of ICG images, various computer software programs have been designed to try to quantify saturation. The VR-RENDER PERFUSION® used by Diana's team [3] uses a light rating system based on an arbitrary scale assigned by the developer with an absolute maximum and a minimum equivalent to 0 . Spy-Q software (LifeCell Corp. $\left.{ }^{\circledR}\right)$, used by Hunter et al. [4], marks areas of maximum perfusion and compares them with other areas of lower intensity, generating a percentage scale from higher to lower degrees of signal and correlating it with vascularization.

The problem with these software products lies in their rating scales, in which the maximum and minimum respond to values arbitrarily attributed by their authors. Our group has designed the SERGREEN program, which creates a scale that does not depend on any arbitrary or subjective value but provides quantitative results in absolute and closed values.

The quantification provided by this scale offers significant improvements when interpreting the results and drawing conclusions, since the data are fully comparable and $100 \%$ reproducible by any system that applies the same method of analysis. There is no dependence on a scale determined by an external developer.

Prior to the section of the inferior mesenteric artery and vein, the two anastomoses were analyzed to establish that the data allowed their assessment as comparable segments. No differences were detected between them. After induction of ischemia, we carried out the analysis separately in the right and left colon.

Two main points should be highlighted with regard to the data obtained for the right colon. First, they were obtained in a uniform manner and without any statistically appreciable variability. Saturation levels remained stable throughout the observation time, thus demonstrating their usefulness as control values. Second, the time interval of 30 minutes between measurements and after each administration of ICG allowed the organism to eliminate the compound from the bloodstream, without any signs of accumulation in the various observations. 
Analysis of the images of the left colon after ischemia induction shows that SERGREEN is able to reflect the significant reduction in ICG saturation in the segment of interest. Once ischemia was established (from 15 min after induction), there were no differences between the measurements over the two hours of observation. This means that once ischemia has been established, and if there are no changes that reverse it, it remains stable. From this point onwards, the measurement can be made at any time.

In the left colon, the mean preischemic saturation value fell from 146 points ( $95 \% \mathrm{Cl}$ : $134.7-159.3)$ to a mean value of 99.1 (95\% Cl: 93.6-104.4), counting all the measurements performed during the period of ischemia. That is, the absolute mean difference after ischemia induction was 47.9 points (95\% Cl: 35.2-60.6).

We also obtained a relative percentage difference of $32.6 \%$, as described above. This relative value shows that any ICG saturation measure below $32.6 \%$ of the initial reference tissue value corresponds to a nonviable ischemic segment that will culminate in tissue necrosis.

Analyses of retrospective series of patients using subjective analog scales have shown an association between the use of ICG and anastomotic leakage. Otero-Piñeiro AM et al [5] reported that the use of ICG modified the colon resection point in more than a quarter of patients, thus helping to reduce the rate of anastomotic leakage. Impellizzeri et al.'s $\left.{ }^{6}\right]$ findings support this hypothesis, suggesting that this association could be demonstrated through randomized studies.

If changes of this kind are already noted with the current use of ICG in routine clinical practice, our hypothesis is that an objective system such SERGREEN can help to optimize anastomoses and reduce the risk of anastomotic leakage.

Even so, a series of steps are still required before our software can be applied clinically. First, we needed to establish the normal values of the various segments of the colon and small intestine (especially the terminal ileum).

To be able to do this, we must eliminate systematic biases. We need to know the optimal time to read the images after injection of ICG at the recommended dose of $\mathrm{mg} / \mathrm{kg}$ of the patient under the same conditions of intraabdominal pressure and luminosity.

Subsequently, the optimal reading distance of the images must be determined. Under these conditions, after repeated observation, we will be able to obtain the baseline saturation values of the various intestinal segments. These values will allow us to obtain cutoff points for making intraoperative clinical decisions based on their sensitivity and specificity.

The intestinal vasculature of the pig is larger in relation to the intestinal wall than in humans, and the vascularized areas are more visible. These areas were not included to avoid variability in the saturations obtained and to avoid the high limits in the ICG saturation values close to 255 , which distorted the image.

The value of the relative decrease in ischemia with respect to nonischemia, $32.6 \%$, is an initial approximation that can help us in decision-making. Extrapolating this value obtained in an experimental model in pigs to routine clinical practice could help us to decide whether an intestinal segment is at risk of ischemia.

The main aim of the application of SERGREEN in colorectal surgery is to improve the viability of anastomoses. It is well known that correct healing is a multifactorial issue. However, adequate vascularization is one of the most important factors. SERGREEN is particularly useful in anastomoses in which the risk of leakage is highest, that is, low colorectal anastomoses that require a protective ileostomy. The combination of technical expertise and the 
optimal vascularization values provided by SERGREEN could benefit the patient well by avoiding the need for ileostomy, with complications and a significant reduction in quality of life that this procedure may entail [ $\left.\left.{ }^{7}\right],{ }^{8}\right]$.

The SERGREEN program can be applied to many other fields of abdominal surgery. In emergency surgery, it can guide the decision whether to resect an ischemic segment after a strangulated hernia or intestinal occlusion. Other possible applications include the study of the sentinel lymph node in cancer surgery $\left[{ }^{9}\right]$, the viability of free grafts in plastic surgery $\left[{ }^{10}\right]$ and the measurement of ICG in liver metastases compared with other space-occupying lesions $[11]$.

A limitation of the study is the fact that the distance from the camera to the tissue was not controlled. Even so, all procedures were carried out by the same team of surgeons, and all images were taken at the same observation time. This circumstance and the animal experimental setting suggest that the results are reliable, given the uniform nature of the readings and the fact that any errors present will be systematic.

\section{Conclusions}

The SERGREEN program allows quantification of ICG saturation and the detection of significant differences between normal and experimental ischemia. Once 15 minutes has passed since the induction of ischemia, ICG saturation can be measured at any time. A reduction in ICG saturation of $32.6 \%$ or greater correlates with complete tissue ischemia.

\section{Declarations}

\section{ACKNOWLEDGMENTS}

We thank the management team of the Parc Taulí Foundation, especially Xavier Gallego for his support for the project; the veterinarians of the Experimental Center of the Parc Taulí University Hospital; the members of the General Surgery and Digestive Diseases Service for their support in the development of the study; Cristina Gómez Vigo for her help in writing the manuscript; and Michael Maudsley for the English translation.

\section{Author Disclosure section}

Dr Xavier Serra-Aracil, Dr Albert Garcia-Nalda, Borja Serra-Gomez, Alvaro Serra-Gomez, Dr Laura Mora-Lopez, Dr Anna Pallisera-Lloveras, Dr Sheila Serra-Pla, Dr Victoria Lucas, and Dr Salvador Navarro-Soto have no conflicts of interest or financial ties to disclose.

\section{Competing interests:}

The authors have no competing interests to declare.

This study has not been presented at any scientific meetings.

\section{Authors' contributions:}

- All the authors agree to the submission of the paper. 
- All the authors: XSA, AGN, BSG, ASG, LML, APL, and LG contributed to the design and writing of the paper.

\section{Category for paper:}

Colorectal.

\section{References}

1. Urbanavičius L, Pattyn P, Van de Putte D, Venskutonis D. How to assess intestinal viability during surgery: A review of techniques. World J Gastrointest Surg 3:59-69 (2011).

2. D. A. Sherwinter, J. Gallagher and T. Donkar. Intraoperative transanal near infrared imaging of colorectal anastomotic perfusion: a feasibility study. Colorectal Disease 15; 91-96 (2012).

3. Diana M, Noll E, Diemunsch P, Barry B, Namer IJ, Demartines N et al. Enhanced-Reality video fluorescence. A realtime assessment of intestinal viability. Ann Surg 259: 700-707 (2014).

4. Moyer HR, Losken A. Predicting mastectomy skin flap necrosis with indocyanine green angiography: the gray area defined. Plast Reconstr Surg 129: 1043-1048 (2012)

5. Otero-Piñeiro AM, de Lacy FB, Van Laarhoven JJ, Martín-Perez B, Valverde S, Bravo R, Lacy AM. The impact of fluorescence angiography on anastomotic leak rate following transanal total mesorectal excision for rectal cancer: a comparative study. Surg Endosc 35: 754-762 (2021).

6. Impellizzeri HG, Pulvirenti A, Inama M, Bacchion M, Marrano E, Creciun M, Casaril A, Moretto G. Near-infrared fluorescence angiography for colorectal surgery is associated with a reduction of anastomotic leak rate. Updates Surg 72: 991-998 (2020)..

7. S. Q. Ashraf, E. M. Burns, A. Jani, S. Altman, J. D. Young, C. Cunningham, O. Faiz and N. J. Mortensen. The economic impact of anastomotic leakage after anterior resections in English NHS hospitals: are we adequately remunerating them? Colorectal Disease 15: e190-e198 (2013).

8. Roy S, Ghosh S, Yoo A. An Assessment of the Clinical and Economic Impact of Establishing Ileocolic Anastomoses in Right-Colon Resection Surgeries Using Mechanical Staplers Compared to Hand-Sewn Technique. Surg Res Pract 2015:749186 (2015).

9. E. Villegas-Tovar, J. Jimenez-Lillo, V. Jimenez-Valerio, A. Diaz-Giron-Gidi, R. Faes-Petersen, A. Otero-Piñeiro, F. B. De Lacy, R. J. Martinez-Portilla, A. M. Lacy. Performance of Indocyanine green for sentinel lymph node mapping and lymph node metastasis in colorectal cancer: a diagnostic test accuracy meta-analysis. Surg Endosc 34: 1035-1047 (2020).

10. Moyer HR, Losken A. Predicting mastectomy skin flap necrosis with indocyanine green angiography: the gray area defined. Plast Reconstr Surg 129: 1043-1048 (2012).

11. Sachiyo Shirakawa, Hirochika Toyama, Masahiro Kido and Takumi Fukumoto. A prospective single-center protocol for using near-infrared fluorescence imaging with indocyanine green during staging laparoscopy to detect small metastasis from pancreatic cancer. BMC Surgery 19: 165 (2019).

\section{Figures}




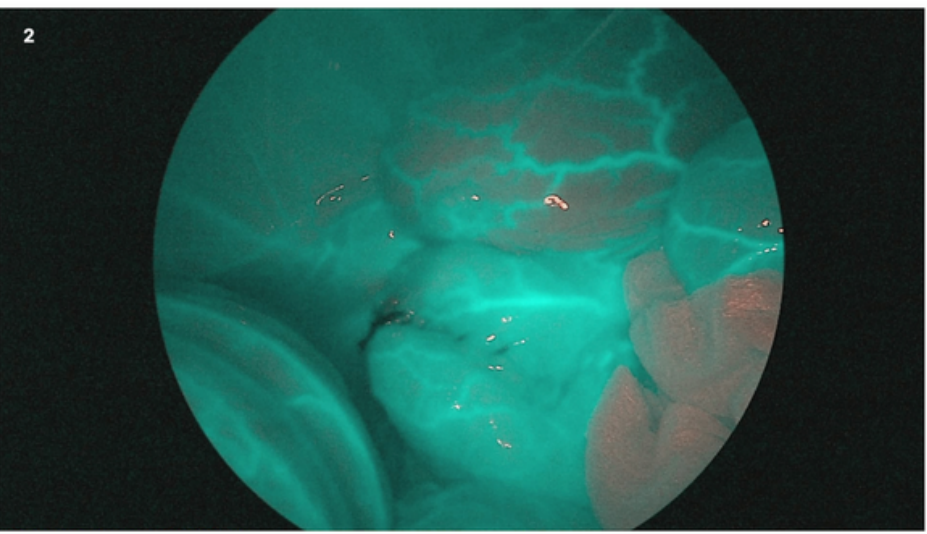

\section{Figure 1}

Laparoscopic image in Spectra A + ICG mode of running suture manual end-to-end anastomosis of the right colon (1), without arterial manipulation, and of the left colon (2), without arterial manipulation.
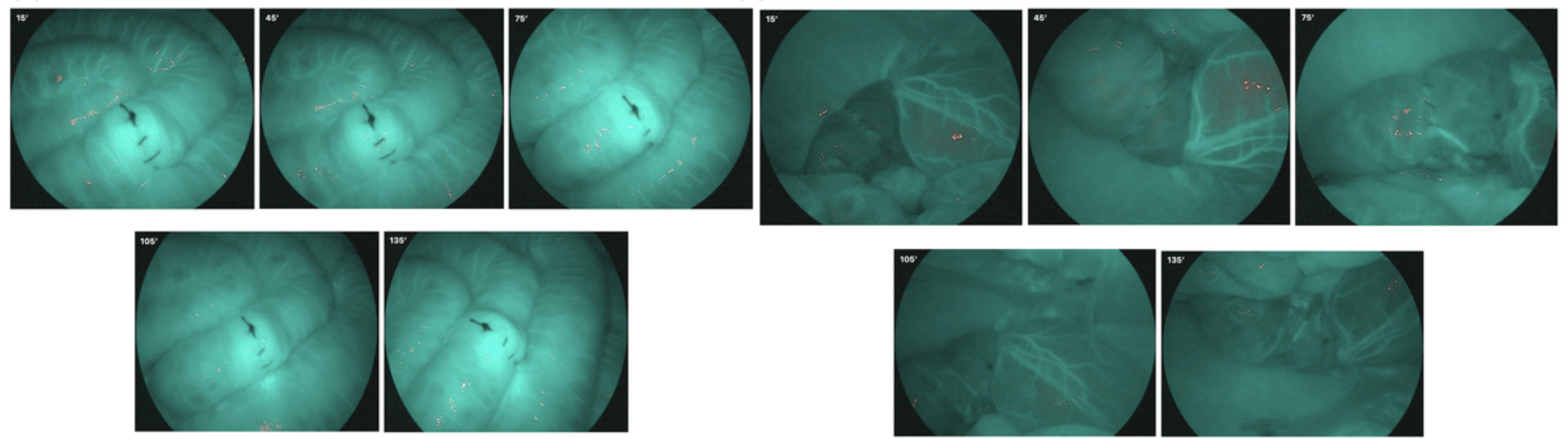

\section{Figure 2}

A. Evolution in images of the right colon after sectioning of the inferior mesenteric artery. Images were taken at 15, $45,75,105$ and 135 minutes after the arterial section. Vascularization remains uniform over time. B. Evolution of images of the left colon after sectioning of the inferior mesenteric artery. Images were taken at $15,45,75,105$ and 135 minutes after the arterial section. Ischemia remains uniform over time.
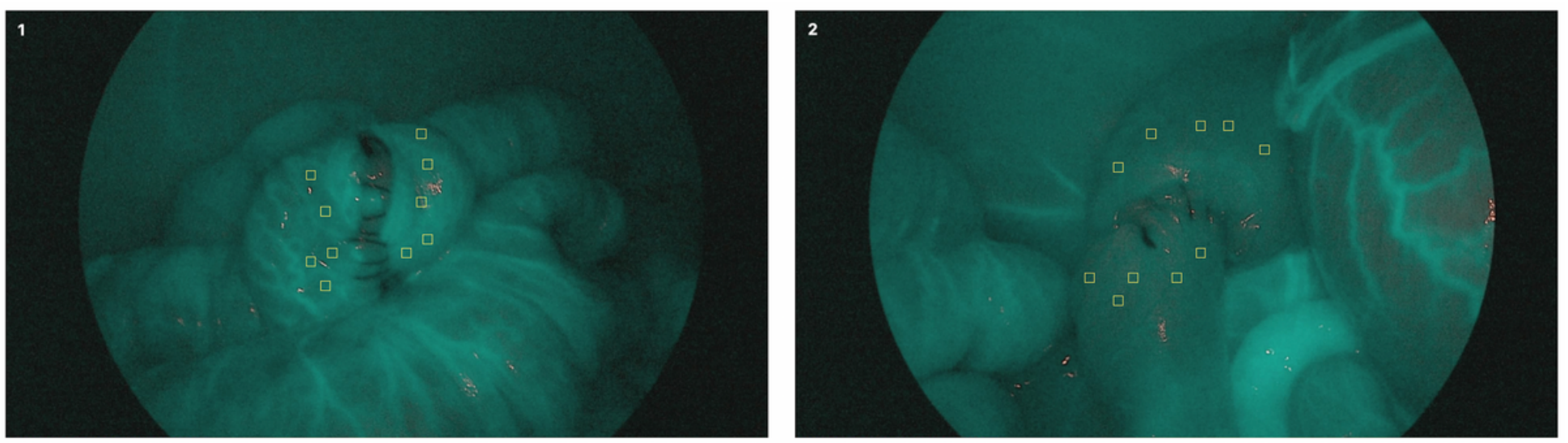

Figure 3 
Ten areas of study of vascularization in the right colon (1) and in the left colon (2) using 10x10 pixel squares, highlighted in yellow circles. Predefined squares are applied over areas of uniform vascularization.
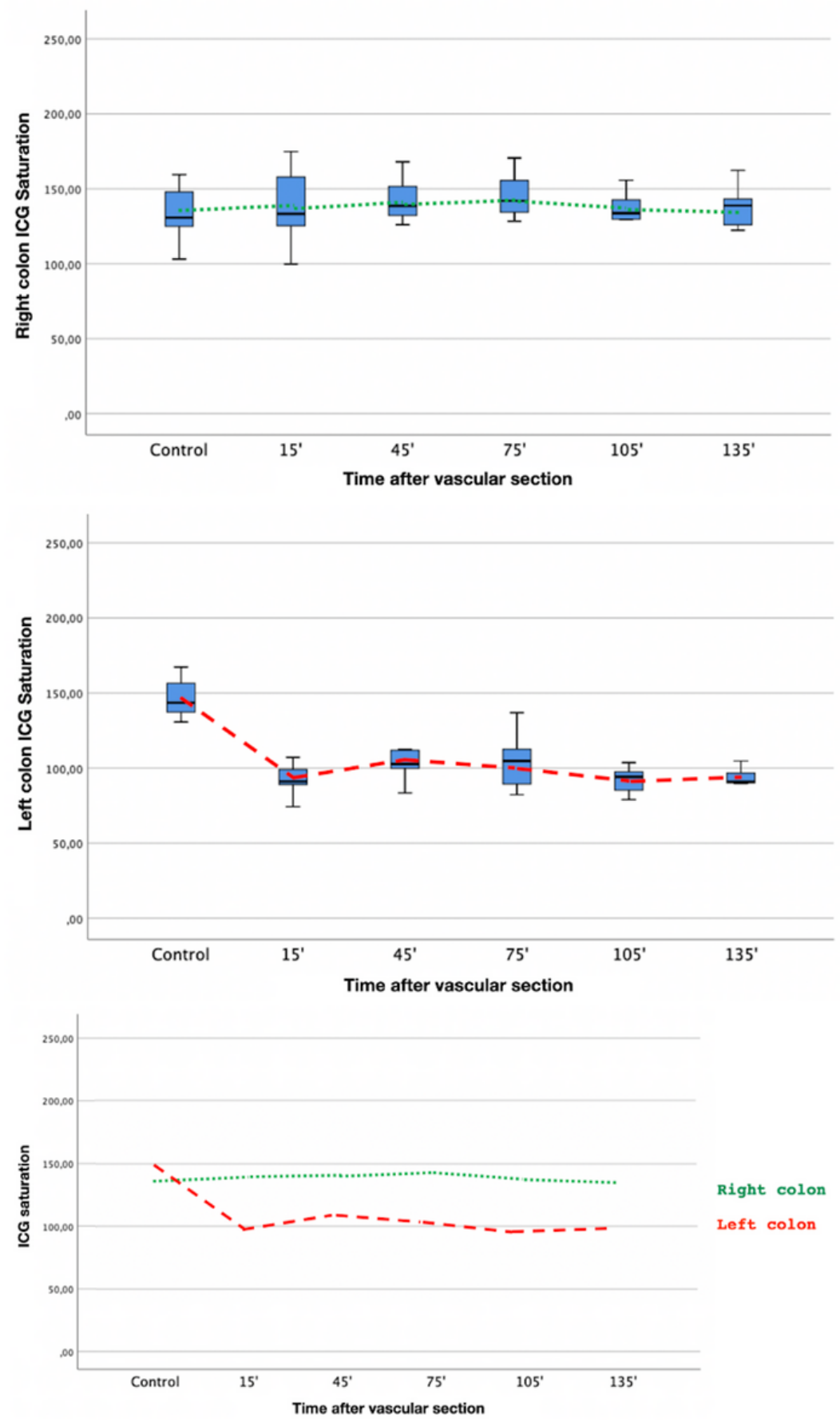

\section{Figure 4}

Boxplot showing the evolution over time from baseline prior to the section of the IMA to minute 135 after its section and that of the vein at the level of the right (1) and left (2) colon. The overlap of the two evolutions over time can be seen in graph 3 , where the solid line represents the right colon and the dashed line the left. 